\title{
GEOGRAFÍAS IMPOSIBLES: \\ HOGAR Y NACIÓN EN LAS NOVELAS DE DONATO NDONGO-BIDYOGO
}

\author{
POR \\ Olga ArBelÁEZ \\ University of Saint Louis
}

El africano vive en peligro desde el nacimiento hasta la muerte, nunca está seguro en ninguna parte, siempre es y será un paria, en su propio país y fuera de él.

El metro, 337

En sus novelas, Las tinieblas de tu memoria negra (1987), Los poderes de la tempestad (1997) y El metro (2007), Donato Ndongo-Bidyogo desarrolla una estética muy particular caracterizada por la mezcla entre la oralidad y el flujo de conciencia del narrador que da como resultado una narrativa de gran belleza estilística. Las tres novelas articulan, desde distintas perspectivas, la misma problemática que tiene que ver con la separación del protagonista de su lugar de origen, es decir, de su familia, de su hogar y de su país. De esta manera, sus novelas giran alrededor de tres nociones espaciales esenciales: el viaje (entendido como el irse o regresar a un cierto lugar de interés de los protagonistas), el hogar (o su carencia) y el país (paraíso terrenal o infierno). Además, dichas nociones están enmarcadas dentro de la particularidad temporal de la memoria personal e histórica de los protagonistas, que está intrínsecamente relacionada con la distancia temporal del protagonista con relación al espacio que recuerda o que habita.

Las tinieblas de tu memoria negra es la narración del viaje simbólico de un protagonista anónimo.A través de sus recuerdos, el personaje se remonta a las experiencias vividas durante su infancia en su hogar, su pueblo y su país natal. Motivado por el sonido de la lluvia que azota los cristales de su ventana en un seminario en Salamanca, el protagonista se embarca en un viaje personal que le permitirá escarbar con nostalgia ${ }^{1}$

1 El uso de la palabra nostalgia, en este ensayo, está determinado por la definición que provee Leo Sptizer en su artículo "Persistent Memory: Central European Refugees in an Andean Land." Normalmente asociada con la ausencia o la separación del hogar o del país de origen, la palabra "[n]ostalgia now also defined 'loss' in a more generalized and abstracted way, including the yearning for a 'lost childhood,' for 'irretrievable youth,' for a 'world of yesterday' from whose ideals and values one had become distanced and detached. In this usage, nostalgia became an incurable state of mind-a signifier of 'absence' and 
en sus recuerdos hasta llegar a ese momento particular, en el presente de la narración en la oficina del rector del seminario, en el que le anuncia que abandona el sacerdocio. Es un momento crucial de su vida en el que se decide a abandonar la misión sagrada que le había sido encomendada por su tío Abeso de ser el salvador de la tribu y de adquirir la sabiduría de los blancos. En ese viaje de la memoria a su pasado y a su lugar de origen, el lector puede dilucidar, poco a poco, las causas por las cuales el protagonista tuvo que salir de la casa paterna, de su pueblo y de Guinea para radicarse temporalmente en España. El evento que desencadena esta decisión radical del protagonista de dejar el sacerdocio, es la recién ganada independencia de su país y su creencia de que "África no necesita únicamente sacerdotes. En mi país ... apenas hay médicos, ingenieros, abogados, qué sé yo ... nativos" (17). Al construir la narrativa como un recuerdo de infancia, a pesar de que el protagonista se encuentra en España, la novela se centra exclusivamente en un espacio geográfico, el de Guinea Ecuatorial y más específicamente en el pueblo natal del protagonista.

La segunda novela y continuación de la primera, Los poderes de la tempestad, tiene lugar solamente en Guinea. Es la narración del viaje de regreso del protagonista a la "tierra prometida" (11). Años después de haber renunciado a ser sacerdote, de haberse hecho abogado y de haber trabajado unos años en España, el protagonista decide regresar acompañado de Ángeles, su esposa blanca y de su hija Rut para recuperar a su familia, su cultura y principalmente para ayudar a su país:

quiero volver a Guinea, Ángeles, para ver a mi familia, después de tantos y tan largos años; aquí y no hago nada ... para luchar contra la injustica y promover el derecho, y debo poner mis conocimientos y la técnica jurídica al servicio de mi país ... y no quiero quedarme aquí definitivamente para no acostumbrarme a una vida sin ideales, no quiero autoexiliarme y cercenar las posibilidades de poner un grano de arena a favor de los míos. (13)

El evento que desencadena este otro momento crucial en la vida del protagonista está relacionado con las noticias que se recibían en España sobre las atrocidades cometidas bajo la dictadura de Macías Nguema Biyogo. A diferencia de la primera novela, el viaje del protagonista al hogar paterno y a la tierra natal es real y físico. A lo largo de este viaje, el protagonista confrontará el recuerdo de esos espacios familiares mantenidos en su memoria por tantos años y matizados por la nostalgia, con su realidad física. El protagonista los encuentra transformados no sólo por el paso del tiempo, sino también por su propio contacto con la cultura de los blancos y por sus experiencias de vida en el mundo de los civilizados en España. A lo largo de todas las penurias que el protagonista

'loss' that could never be made into 'presence' and 'gain' except through memory and the creativity of reconstruction" (376).

Revista Iberoamericana, Vol. LXXX, Núms. 248-249, Julio-Diciembre 2014, $1041-1056$ ISSN 0034-9631 (Impreso)

ISSN 2154-4794 (Electrónico) 
y su familia tienen que vivir en Guinea, tanto su país como su hogar paterno dejarán de ser la tierra prometida. Guinea llegará a convertirse, durante el relato, en un lugar fétido, insalubre y lleno de horrores; "un pueblo habitado por espectros" (32) y un "infierno" (72).

El metro, la tercera novela, introduce al lector en el mundo interior de otro joven africano, Obama Ondo, cuyo único sueño es el de establecer un hogar. Sin embargo, a lo largo de su vida, las circunstancias se presentan de tal manera que, cuando parece que está a punto de lograr su sueño, algo trágico sucede y tiene que desplazarse a un nuevo lugar y empezar de nuevo. Su vida es un constante deambular de un pueblo a otro, de ciudad en ciudad, primero en su país natal, Camerún, después a otros países vecinos y, finalmente, fuera del continente africano, en la nueva tierra prometida, España. El lector acompañará al protagonista en este viaje que parece eterno y comparte sus penurias hasta que su destino lo llevará a encontrar la muerte en el metro de Madrid. Aunque, Obama Ondo "había determinado que su muerte nunca sería una muerte anónima" (21), su vida se extinguirá lentamente en la soledad de un vagón vacío y en movimiento del metro de Madrid, acompañado por el espíritu de su madre muerta, precisamente cuando parecía que sus sueños empezaban a hacerse realidad. Obama Ondo terminará convirtiéndose en una estadística más en un país que no es el suyo, dónde no conoce a nadie y dónde nadie lo conoce, sin ningún tipo de documentación que lo reconozca como individuo o como ciudadano de algún lugar del mundo.

Las tres novelas giran en torno al deseo del protagonista de volver y/o establecer un hogar en su país natal. Tanto para el protagonista anónimo de Las tinieblas y Los poderes, como para Obama Ondo de El metro, este deseo nunca logra realizarse. En The politics of Home, Rosemary Marangoly George establece que la noción de hogar es una construcción social, tan politizada como la noción de nación. Además, la autora indica que, "[t]he word home immediately connotes the private sphere of patriarchal hierarchy, gendered self-identity, shelter, comfort, nurture and protection ... As imagined in fiction, "home" is a desire that is fulfilled or denied in varying measure to the subjects (both the fictional characters and the readers) constructed by the narrative" $(1,2)$. Los protagonistas de Ndongo-Bidyogo no carecen de un lugar donde vivir pero añoran la estabilidad y la protección de ese espacio específico localizado en su país natal al que puedan considerar su hogar. La noción de hogar para ellos es evidentemente un espacio de pertenencia no sólo a un país sino a una cultura y a una raza específicas. Según Marangoly George:

One distinguishing feature of places called home is that they are built on select inclusions. The inclusions are grounded in a learned (or taught) sense of kinship that is extended to those who are perceived as sharing the same blood, race, class, gender, or religion. Membership is maintained by bonds of love, fear, power, desire, and control. Homes are manifest on geographical, psychological and material levels. They are places that

Revista Iberoamericana, Vol. LXXX, Núms. 248-249, Julio-Diciembre 2014, 1041-1056 ISSN 0034-9631 (Impreso)

ISSN 2154-4794 (Electrónico) 
are recognized as such by those within and those without. They are places of violence and nurturing. A place that is flexible, that manifests itself in various forms and yet every reinvention seems to follow the basic pattern of inclusions/exclusions. Home is a place to escape to and a place to escape from. Its importance lies in the fact that fought for and established as the exclusive domain of a few. It is not a neutral place. It is community. Communities are not counter-constructions but only extensions of home, providing the same comforts and terrors on a larger scale. Both home and community provide such substantial pleasures that have been so thoroughly assumed as natural that it may seem unproductive to point to the exclusions that found such abodes. (9)

Es por esto que, para los personajes de Ndongo-Bidyogo, imaginar el hogar es un acto tan político como el concepto de imaginar la nación que Benedict Anderson postulaba. El hogar ancestral que ellos añoran, es el lugar que les permite recuperar el pasado perdido, las tradiciones y lenguas casi olvidadas y la conexión con esa cultura marginalizada por los colonizadores europeos. Además, es el espacio que les permite imaginar una vida futura con objetivos e ilusiones en la que el proyecto de establecer un hogar trasciende la noción de hogar asociada con el antiguo orden pre-colonial e incluso con el colonial. Para estos personajes, hogar y nación son sinónimos porque tienen la visión de llevar el progreso y la modernidad a su familia, a su comunidad, a su país y a todo el continente africano.

En Las tinieblas de tu memoria negra, Ndongo-Bidyogo sitúa a su joven protagonista en un pequeño pueblo de Guinea durante las últimas décadas de la colonización española. La narración retrospectiva cubre un período en la vida del niño desde los siete hasta los trece años, edad en la que abandona el pueblo para irse a educar a un seminario católico de blancos en Banapá. Durante sus años formativos, como resultado del colonialismo, la vida del niño está determinada por el conflicto constante entre los valores europeos y católicos del colonizador y los valores de su cultura fang. Según Baltasar Fra-Molinero: "Ambos modelos de vida se presentan como opciones opuestas y enemigas que luchan por ganarse el alma del niño, el adolescente y el adulto" (49). A lo largo de la novela, el lector observa el proceso de colonialismo mental y espiritual del protagonista y la tensión entre el modelo de aquí y el modelo de allá que forjaron su vida, sus creencias y su visión del futuro. El protagonista sirve como símbolo de la experiencia de colonización de la nación guineana.

La descripción de aldea natal del protagonista de Las tinieblas revela un país que se encuentra en proceso de cambio en el que el orden (desorden) ancestral milenario está siendo reemplazado por un nuevo orden y, como resultado, la geografía tanto física como social de la nación está siendo modificada. El espacio tradicional está siendo transformado, no sólo por el modelo de civilización traído por los colonizadores españoles, sino también por su cultura y su religión. Su pueblo era, 
[u]na aldea como todas allá ... con hileras de casas de nipa, de adobe y de calabó diseminadas con improvisación, como si mañana no fueran a estar allí, a ambos lados de la polvorienta carretera, con una iglesia que se distingue del resto de las chozas por la tosca cruz de madera que la corona, y con una escuela alargada, construida igualmente con materiales del país que cada cierto tiempo hay que remozar. (22)

Aunque la iglesia y la escuela han sido construidas al lado de las desordenadas chozas de adobe y son hechas con los materiales autóctonos aunque efímeros de la región, su presencia da testimonio de las transformaciones espaciales que se están llevando a cabo en todo el país.

La casa del protagonista, hecha de cemento y con techo de cinc, apunta tanto a esas futuras transformaciones del espacio vital y comunal del país, como a un nuevo orden social y económico que los colonizadores esperan implantar en el país. Su "padre había abandonado, a la vista de todos pero imperceptiblemente, la tradición para insertarse en la civilización" (21). Además, "había sido uno de los primeros, sino el primero, de la comarca, en abrir una finca de café, símbolo de un nuevo tiempo que anunciaba la modernidad" (21). Gracias a ese gesto, su padre se había ganado el respeto de todos los habitantes del pueblo y el de los colonizadores.

La escuela del pueblo, "tierra polvorienta bajo un techo de nipa aún verde" (25), junto con la iglesia, es el edificio más importante del pueblo y allí los niños reciben lecciones sobre historia, geografía, religión y lengua españolas. Aún en este "edificio" humilde de construcción tradicional se encuentra la presencia del proyecto civilizador de los colonizadores. El aula estaba decorada con un retrato de Francisco Franco, "el Invicto Caudillo de España por la Gracia de Dios" (27), un retrato de El Fundador y un enorme crucifijo del Redentor Jesucristo. Estos retratos son símbolos poderosos del ejercicio político y religioso del poder colonial. El retrato de El Fundador apunta al intento por parte de los colonizadores de articular una Historia de la comarca y del país, que empieza con el establecimiento de las primeras colonias españolas, lo cual implica la negación del pasado de la tribu mantenida por sus habitantes a través de la tradición oral.

A pesar de la presencia de la escuela, de la iglesia y de la casa con techo de cinc del padre del protagonista, la aldea es todavía un espacio en el cual el proyecto colonial no ha sido completado. En su geografía cohabitan las construcciones pre-coloniales (tradicionales) con las nuevas construcciones e instituciones coloniales. El tío Abeso sigue siendo el jefe de la tribu y sigue siendo el encargado de mantener y defender la cultura ancestral de los fang frente a los colonizadores. No obstante, la identidad de este espacio cultural y físico es ya ambivalente y sirve de testimonio de que dos realidades no sólo físicas, sino culturales coexisten, a pesar de la resistencia cultural de sus habitantes.

El internado adonde el protagonista fue enviado después de terminar sus estudios elementales, estaba situado en la capital del distrito y aquí la geografía ya está colonizada.

Revista Iberoamericana, Vol. LXXX, Núms. 248-249, Julio-Diciembre 2014, 1041-1056 ISSN 0034-9631 (Impreso)

ISSN 2154-4794 (Electrónico) 
El internado “[e]ra un caserón inmenso, con un pórtico amplioy fresco donde no podíamos refrescarnos, un patio grandioso que chapeaban los internos castigados, rodeado de plantaciones de café que también chapeábamos y recolectábamos los internos" (114). Los encargados de la educación de los niños eran sacerdotes, quienes tenían además una gran influencia en los pueblos de la comarca. El prestigio del "reverendo Padre Superior había crecido de tal forma que todas las tribus de la comarca desautorizaron a sus hechiceros y se convirtieron al catolicismo" (121). El edificio del internado rodeado de plantaciones de café da testimonio de que el proceso de colonización estaba más adelantado en otras regiones y en pueblos más grandes que la aldea del protagonista. El paisaje natural y las edificaciones estaban siendo transformadas o reemplazadas por nuevas construcciones al estilo europeo en todo el país.

Una característica del colonialismo, según Jürgen Osterhammel, es la negativa de los colonizadores de hacer concesiones culturales a las sociedades subyugadas puesto que esperaban que los colonizados sufrieran una extensiva aculturación de sus valores y sus costumbres europeas (16). En Las tinieblas se observan distintas manifestaciones de resistencia cultural por parte de los guineanos que operan en forma paralela a los mecanismos de aculturación y que se traducen no solamente en una resistencia hacia los modelos de los opresores sino a la continua defensa de su tradición y formas de vida. La novela da fe tanto de la aculturación como de la resistencia al proyecto colonialista español en Guinea. Sin embargo, sometido a este choque de culturas, el protagonista crece en medio de estos dos mundos y va desarrollando una identidad múltiple y fragmentada que va a exteriorizar a lo largo de la narración. Su respuesta a la tensión entre el choque de culturas y a su fragmentación interior es la de anunciar, hacia el final de la novela, que va a hacerse sacerdote. Es un intento desesperado de su parte, por un lado, de conciliar los dos mundos que forman parte de su ser y, por otro lado, de contribuir al progreso de su gente. Al salir del pueblo, el joven de trece años, transformado por la dicotomía de culturas en un sujeto colonial, empieza un viaje personal y espiritual que paulatinamente lo va a separar mental y físicamente de su hogar y de su tribu, y que eventualmente lo llevará, a los diecinueve años, a vivir en el país del colonizador, España. Como sujeto colonial, el protagonista corresponde a la figura de hibridez que Laurence Grossberg propone para agrupar a aquellas identidades subalternas que habitan una frontera situada entre dos identidades que compiten. El subalterno híbrido habita un tercer espacio que no es ni el espacio del colonizador ni el espacio del colonizado. De acuerdo con Grossberg, el subalterno vive en la frontera y, por lo tanto, el protagonista de las dos novelas vive en esta frontera cultural y espacial independientemente de si se encuentra físicamente en España o de vuelta en Guinea. Vive una identidad fronteriza que lo separa y lo confronta a la vez, tanto con su cultura ancestral africana, como con la cultura española asimilada a lo largo de su vida. Después de la independencia de Guinea, el proyecto de vida del protagonista es el mismo que el que le había encomendado el Tío Abeso: adquirir la sabiduría de los blancos y salvar a la tribu ya no como sacerdote sino como abogado.

Revista Iberoamericana, Vol. LXXX, Núms. 248-249, Julio-Diciembre 2014, $1041-1056$ ISSN 0034-9631 (Impreso)

ISSN 2154-4794 (Electrónico) 
Por lo tanto, aunque habita en ese tercer espacio, en su imaginación, su espacio vital (hogar) identitario fue desde siempre Guinea, el espacio del colonizado.

En Los poderes de la tempestad, la hibridez cultural del protagonista se hará cada vez más patente a medida que interactúa con los guineanos y con el espacio físico. A lo largo de la novela, el lector es testigo de la desilusión paulatina del protagonista al volver a un país que no corresponde al del recuerdo conservado en la memoria a lo largo de sus muchos años de exilio. Si bien es cierto que encuentra la misma naturaleza tropical de sus recuerdos, la naturaleza misma parece transformada. El paisaje es "[e]l mismo paisaje exuberante, embriagador, inmensamente bello, pero de una belleza tétrica: como un pueblo habitado por espectros” (32).

Antes de regresar a su país, el protagonista lleva ya varios años muy seguro de su identidad como guineano y como fang, por eso, la vida en medio de los blancos le parece un sin sentido. A pesar de que había constituido su propia familia en España, es claro que para él su verdadera familia y su verdadero hogar son los que dejó atrás en su tierra natal:

\begin{abstract}
¿No puedes comprender que esté harto de vivir solo en España, sin más familia que el amor de Ángeles, sin más ilusión que ver crecer a Rut, alejado de mis padres, de mis hermanos, de todos vosotros? Te aseguro que tener mujer, una hija y ciertas comodidades no compensa la tremenda soledad del expatriado. No tengo complejos raciales, pero llevo trece años siendo negro en una sociedad de blancos en la que cada día tienes que demostrar que vales al menos tanto como el más listo de ellos, una oposición continua, no te lo puedes imaginar. Tengo una carrera, sí, pero no fui a España a vivir, sino a estudiar y regresar, pues sobran abogados en España y aquí apenas si los hay. Quisiera ayudar a mi familia y a mi país. (75)
\end{abstract}

Sin embargo, la certidumbre sobre su africanidad, o de su pertenencia al espacio del colonizado, va a ponerse a prueba desde el momento de poner pie en su tierra natal. Cada contratiempo por pequeño o grande que fuera va a cuestionar su lealtad con su país y con sus compatriotas. Humillado y enfurecido por el trato que él y su familia reciben en el aeropuerto, el protagonista llega a

descubrir que Guinea se había convertido de verdad en un infierno en el que mandaba un puñado de mozalbetes ociosos y analfabetos, sólo atentos a descubrir las miserias humanas para refocilarse en ellas, hasta el punto de que parecían encontrar un placer especial en el sufrimiento de sus semejantes. ¿Ya no existía ese guineano cortés, comprensivo y hospitalario, vehemente pero veraz, que tantas había ponderado ante mis compañeros de estudios, ante mis amigos españoles en las noches de vino tinto en los mesones de Madrid, y, sobre todo, ante Ángeles? ¿Me estaría llamando mentiroso, empezaría a dudar de mí? (33-34)

Revista Iberoamericana, Vol. LXXX, Núms. 248-249, Julio-Diciembre 2014, 1041-1056 ISSN 0034-9631 (Impreso)

ISSN 2154-4794 (Electrónico) 
No sólo las personas le parecen distintas sino, también su forma de relacionarse con ellas ha cambiado. El rechazo al toque amable de su primo, le permite darse cuenta que es él quien ha cambiado y quien no puede entender la mentalidad de los suyos:

Dios mío, ayúdame a sobrevivir en este mundo que es el mío pero que ya se me escapa como si no fuera el mío, tengo tanta confusión en mi alma como si me despertara de repente en una tierra lejana, mi mentalidad ha cambiado tanto que ya no me reconozco como negro, como bantú, como africano, como guineano nacido en la misma tribu, en el mismo clan, en el mismo poblado, entre la misma gente que el primo Mbo, su padre, el tío Abeso, es hermano de mi padre pero ya nos distancian hasta los gestos más nimios y las actitudes más inocentes, qué será de mí si continúo con esta manera de pensar, de enredarlo todo con la reflexión y la fantasía. (58)

Es así como el protagonista por primera vez adquiere conciencia real de que habita ese tercer espacio fronterizo entre los dos mundos que ha conocido a lo largo de su vida.

El olor de la tierra, tantas veces mencionado con nostalgia en Las tinieblas, le repugna cuando visita la humilde vivienda de su primo Mbo: "El vaho putrefacto que os recibió a la entrada de la vivienda cuartelera del primo Mbo no fue sino el preludio de todas las contrariedades que os tocaría sufrir a lo largo de aquella aventura inexplicable. No estabas ya acostumbrado a los olores de la tierra" (39). Así mismo, la estética del espacio urbano de la capital también le choca, no solamente porque se ha acostumbrado al orden y a la normatividad de las ciudades y pueblos europeos, sino también porque la ciudad y los nombres de las avenidas y de los edificios principales habían sido cambiados. Santa Isabel pasa a ser Malabo, "Malabo, Malabo, Malabo: apréndetelo de memoria que no te vayan a acusar de colonialista por no adaptarte a la nueva toponimia" (67). La Avenida Generalísimo Franco se convierte en la Avenida Francisco Macías Nguema, el Banco Central se convierte en el Banco de Guinea Ecuatorial, los Viajes Fernando Poo recibe el nombre de Agencia Marítima Nacional. En general, al protagonista le impresiona el "abandono a que estaba llegando la ciudad" (69). En otro momento, el observar una finca en medio de la ciudad le produce una impresión desagradable y se pregunta “¿[c]ómo permiten plantar plátanos y malanga en plena ciudad?”(87). ${ }^{2}$ En este punto de la novela, se hace claro que los años vividos fuera de su país, en España, han modificado

2 En sociedades poscoloniales olvidar el pasado colonial es imposible puesto que el paisaje ha sido transformado por los colonizadores. En Guinea, una de las estrategias para reescribir el pasado colonial consiste, como se observa en Los poderes, en eliminar los nombres asociados con el imaginario del colonizador y cambiarlos a nombres autóctonos. De acuerdo con Brenda S.A. Yeoh " [i]n the symbolic reproduction of the landscape, the postcolonial strategy here is not so much to erase the colonial imprint but to recolonize with a different script. A script that destabilizes the logic of colonial imaginings by offering its own accents in counterpoint to what was there before" (171).

Revista Iberoamericana, Vol. LXXX, Núms. 248-249, Julio-Diciembre 2014, $1041-1056$ ISSN 0034-9631 (Impreso)

ISSN 2154-4794 (Electrónico) 
la relación del protagonista con su entorno social y físico.Ya no puede aceptar ese orden espacial donde cohabitaban el orden pre-colonial y el colonial que aparecen tan naturalmente aceptados en sus recuerdos de sus vivencias infantiles en Las tinieblas. Si bien es cierto que el momento histórico en que el protagonista vuelve a su país es distinto del momento de su partida, es su mentalidad la que ha cambiado, transformada por el contacto con la cultura de los blancos. Este país que él ya no entiende sigue siendo, como en su niñez, un espacio compuesto de una mezcla de espacios pre-coloniales con espacios coloniales que fueron "nacionalizados" después de la independencia. En algún sentido, la Guinea postcolonial no es muy diferente de la Guinea colonial que él conoció, pero a él le parece un país completamente distinto. Guinea deja de ser la tierra prometida para convertirse en un espacio de exclusión, en una "tierra ingrata" que devoraba a todos sus hijos" (111) y la idea de volver a España empieza a surgir en su mente, mucho antes de que su vida y la de su familia estuviera en peligro.

Antes de volver a España, el protagonista decide viajar a su aldea natal para visitar a su familia. Resulta paradójico que la memoria le falla completamente cuando no reconoce a su pueblo natal tantas veces evocado en la memoria. Tiene que ser informado por el chofer del autobús que ya habían pasado el pueblo y que además habían estado parados allí por más de una hora. Si bien es cierto que la aldea había sido transformada por el paso de una carretera y que la capillita de su niñez con sus paredes de barro y techo de nipa "se había convertido en una grande pero irregular construcción de bloques de cemento cubierta con chapas de cinc" (184), el resto del espacio parece permanecer igual. Su descripción de la gente del pueblo, a quienes no reconocía tampoco, no difiere mucho de algunas de sus descripciones que presenta en Las tinieblas.

El reencuentro con su familia después de tantos años de ausencia y de haber perdido en los recuerdos sus rasgos físicos es el momento más importante de este viaje de regreso al hogar paterno y a su país. Es el único momento en la novela en que el país se convierte en un espacio de inclusión. Sus padres lo acogen con extraordinario cariño tanto a él como a su esposa blanca. Su familia, sin embargo es distinta. Tiene muchos hermanos a los que nunca había conocido y el Tío Abeso vivía ahora en el pueblo perseguido por razones políticas. El orden social pre-colonial que cohabitaba con el colonial durante sus años infantiles (colonizador/colonizado) había sido destruido por la hecatombe ideológica de la Guinea postcolonial. Tanto su país como su aldea ya no son hogar sino sitios de exclusión para el protagonista. La única opción que tiene es la de volver a España, volver a ser negro entre blancos, para reunirse con su esposa e hija y para denunciar lo que está sucediendo en el país.

En contraste con el protagonista de las dos primeras novelas, Obama Ondo, el protagonista del metro, no es un sujeto fragmentado y dividido por el peso de vivir en un espacio cultural intermedio producido por el hecho de haber crecido entre dos culturas en conflicto. En esta novela, Ndongo-Bidyogo explora una nueva faceta de

Revista Iberoamericana, Vol. LXXX, Núms. 248-249, Julio-Diciembre 2014, 1041-1056 ISSN 0034-9631 (Impreso)

ISSN 2154-4794 (Electrónico) 
la problemática africana que tiene con ver la realidad de aquellos individuos que se desplazan a otros lugares buscando mejores oportunidades y que están dispuestos a perder la vida en el intento. Son individuos, como Obama Ondo, que pierden la conexión con su lugar de origen y que, preocupados por la necesidad cotidiana de la supervivencia, no se pueden dar el lujo de experimentar ningún tipo de sentimiento patriótico, ni se inscriben dentro de una identidad cultural específica. En este sentido, El metro no es una novela del exilio, puesto que la noción de exilio parte de la premisa de que existe una estrecha conexión entre un individuo y su lugar de origen que se manifiesta en una relación dialéctica entre el aquí y el allá, relación que es muy clara en las novelas anteriores. En este sentido, El metro es una obra que puede agregarse al corpus cada vez más abundante de las novelas de inmigración. Según Rosemary Marangoly George, "[t]he immigrant genre is often marked by a detached and unsentimental reading of the experience of "homelessness"-which has ... often been read as indicative of the apolitical stance adopted by immigrants" (175). Para Marangoly George la falta de conexión del individuo con su hogar o lugar de origen, característica predominante en la novela de inmigración, sirve para demostrar precisamente la carencia, en dicho individuo, de sentimientos de pertenencia a un hogar e incluso de cualquier sentimiento nacionalista.

El metro presenta la problemática de aquellos individuos que por diversas razones, culturales y/o económicas no están conectados a un lugar específico sino que habitan en espacios culturales, físicos y legales vacíos producto de los procesos deshumanizados que genera la práctica de las políticas actuales de la globalización. Utilizando la noción acuñada por Marc Augé, El metro podría considerarse como la novela del "no lugar," puesto que Obama Ondo toda su vida ha habitado en lo que el antropólogo francés ha denominado como los "no lugares"de la postmodernidad.

El epígrafe de la novela es tomado de un poema titulado "En el Metro" del poeta español de la generación del cincuenta y seis, Carlos Álvarez: "Todo cabe, tal vez, en la imprecisa, / malograda expresión de los que ahora/ me acompañan viajando en este viejo, / casi humano vagón que me conduce. / Que también me conduce no sé adónde" (11). Como el título de la novela, el epígrafe hace énfasis no en el protagonista, eje de todo el texto, sino en el lugar que le permite ganarse la vida y dónde termina cruelmente su existencia: el metro. Tanto el primer capítulo como el último tienen lugar en el presente de la narración en el momento en que Obama Ondo trabaja como vendedor ambulante en el metro. De los capítulos dos hasta el dieciocho la novela presenta la narración retrospectiva de su vida empezando con la historia de su padre y de su abuelo hasta llegar a las circunstancias que lo llevaron a vivir en Madrid y a buscarse la vida en el metro durante los meses de invierno.

El fragmento del poema de Álvarez apunta a la sensación de anonimidad y soledad que alguien experimenta cuando viaja en el metro rodeado de personas desconocidas a las que probablemente nunca más va a volver a ver en su vida. Evoca lo efímero, lo 
rápido lo inmanente, lo que no perdura, lo inasible, lo fugaz, lo etéreo, características de la forma de vida de la posmodernidad. Los versos anticipan no solamente el cruel final de Obama Ondo, sino que sirven para articular la experiencia de sus veinte y ocho años de existencia . Todo en su vida ha sido y es, como su ocupación final, ambulante.

Para Augé el metro es un ejemplo perfecto de lo que él ha denominado como un "no-lugar": "Si un lugar puede definirse como lugar de identidad, relacional e histórico, un espacio que no puede definirse ni como espacio de identidad ni como relacional ni como histórico, definirá un no lugar."(83). Esto quiere decir que los "no lugares" son lo opuesto a los lugares antropológicos de la modernidad, es decir, al hogar, la comunidad y/o la nación. No se trata, sin embargo de lugares concretos geográficos, sino de espacios en los cuales se está de paso y en los que se ejecuta una acción determinada (viajar, comprar, vender, descansar, etc.). El "no lugar" por no ser relacional es el espacio de la individualidad solitaria, de lo provisional y de lo efímero. No hay oportunidad para el establecimiento de relaciones entre el individuo y el espacio o entre un individuo con otros. El "no lugar" tampoco permite la formación de la Historia puesto que, según Auge, "[a]llí reinan la actualidad y la urgencia del momento presente. Como los no lugares no se recorren, se miden en unidades de tiempo ... Se viven en el presente" (107).

Cuando Obama Ondo trabaja en el metro su solitaria espera por un comprador rodeado por los millares de transeúntes que pasan por allí, siempre de prisa, le dan el tiempo para meterse dentro de sí mismo, remontarse al pasado y reflexionar sobre su vida para tratar de determinar el momento en que ésta se trunca. Esta descripción sirve para ilustrar la noción del "no lugar" discutida anteriormente:

Obama Ondo iba siempre ensimismado en el Metro, a solas con sus cuitas aunque le rodeaban otros seres humanos tan encerrados en sí mismos como él ... Lambert Obama Ondo nunca había imaginado que los derroteros de su vida le condenarían a ser sólo un pobre vendedor ambulante ... fijó su mirada en esos escasos productos que constituían su negocio y todo su mundo, dispuesto a esperar lo que le proporcionara el nuevo día. Estaba entrenado para ser paciente. Y aunque sus ojos se elevaban de vez en cuando del suelo para merodear sobre las figuras que pasaban a su alrededor sin fijarse en él, ajenas por completo a que su subsistencia dependía de su capricho de comprarle unos pendientes de hojalata ... notó claramente cómo su espíritu abandonaba allí su cuerpo dolorido ... y volaba despacito hacia el pasado. (14-19)

Es ese viaje al pasado, que ocupa los siguientes capítulos de la novela, en el que se puede rastrear la incapacidad de Obama Ondo, por diversas razones, para establecer una conexión con aquellos lugares antropológicos de la modernidad como el hogar y la nación. Dicha carencia servirá para demostrar que su vida transcurrió siempre en un "no lugar" en el sentido de Augé.

Su abuelo, el jefe Ebang Motuú había sido el "último guardián de las esencias tradicionales de los fang en la comarca de Mbalmayo" (24). Su padre Guy Ondo Ebang,

Revista Iberoamericana, Vol. LXXX, Núms. 248-249, Julio-Diciembre 2014, $1041-1056$ 
por el contrario, se había alineado con los colonizadores y se había empleado como acólito de los sacerdotes franceses que estaban encargados de enseñar las nuevas doctrinas a los habitantes de la comarca y, por eso, había abandonado su pueblo natal. El primer hogar de Obama Ondo fue "un cobertizo agregado a la residencia de los religiosos que ellos convirtieron en un hogar santificado por su inmensa devoción a la Virgen de Lourdes" (40-41). Aunque es un hogar en el sentido tradicional occidental del término, desde la perspectiva de los fang no es un hogar porque el terreno donde está construida la casa no pertenece a Guy Ondo sino a los misioneros. Contrariado por la decisión de Guy Ondo de renunciar a su cultura y de adoptar la de los blancos, el abuelo Ebang Motuú lo declara indigno hijo de su tribu y antes de morir lo deshereda y no permite que entre en posesión de la casa ancestral y de la tierra que había acumulado en su vida gracias a su estatus de jefe de la tribu y a su importancia en la aldea.

Con el tiempo, Guy Ondo vuelve a su aldea natal convertido en catequista. El segundo hogar en el que se instala la familia también pertenece a la Misión aunque era inferior al que tenían antes, "carecía de tela mosquitera en ventanas y puertas" de luz eléctrica, era sucio y rodeado de basuras (50). Obama Ondo quien, en el otro pueblo, había crecido como hijo de potentado sin realmente haberlo sido, pierde todos esos privilegios cuando regresan a la aldea del abuelo. Por no vivir en el hogar ancestral y por ser su padre catequista, Obama Ondo es considerado como el hijo del proscrito y los otros niños de la aldea lo llaman "blanquito embustero" (51). No obstante, poco a poco se gana el respeto de los otros niños porque sabe más que el maestro. Así mismo, la vuelta a la aldea de su abuelo le permite aprender la forma de vida y las tradiciones de los fang. Aprendió a cazar en el bosque, por ejemplo, y empezó a llevar comida a su casa. En poco tiempo, fue como cualquier otro niño de la aldea aunque seguía con el estigma de ser el hijo del catequista.

A raíz de la muerte de su madre, unos años después de regresar a la aldea, Obama Ondo "se dio cuenta de las razones profundas del distanciamiento de su padre del abuelo ... Tomó en secreto el partido del venerado jefe Ebang Motuú ... supo que él haría lo imposible para restaurar el orden antiguo y devolverle a la tribu su esplendor" (69). Por eso, decide ocupar la tierra que había pertenecido a su abuelo para construir allí su propio hogar:

A nadie extrañó que, cuando creyó llegado el momento de abandonar el hogar paterno y asentarse por su cuenta, proclamando así su mayoría de edad, eligiese volver al solar que ocupara su abuelo, el muy recordado jefe Ebang Motuú, donde edificó su propia casa. Hacía ya tiempo que a Obama Ondo le daba vergüenza que su padre estuviese llegando a la edad provecta sin tener ni siquiera un techo propio bajo el cual cobijarse, ya que, al fin y al cabo, vivía de prestado en la casa financiada por los misioneros y construida por el pueblo para el catequista, que sus hijos no podían heredar, porque pertenecía a la Misión y se asentaba sobre terrenos de otra tribu. Un yendjok que

Revista Iberoamericana, Vol. LXXX, Núms. 248-249, Julio-Diciembre 2014, $1041-1056$ ISSN 0034-9631 (Impreso)

ISSN 2154-4794 (Electrónico) 
mereciera ser respetado no podía andar mendingando un trozo de tierra donde edificar su hogar. (106-07)

Sin embargo, para fundar un hogar y ser un digno descendiente de su abuelo debía casarse y tener hijos. Durante su adolescencia tiene un largo romance con Anne Mengue, una joven del pueblo. Planea casarse con ella pero cuando se decide a hacerlo su padre anuncia que va a contraer matrimonio por segunda vez con la madre de Anne. Según las costumbres de la tribu, con este matrimonio, Obama y Anne se convertirían en hermanos y eso anula cualquier posibilidad para ellos de casarse, a pesar de que ya para entonces Anne llevaba en su vientre un hijo suyo. Irónicamente la misma tradición que Obama Ondo estaba dispuesto a rescatar para sí y para su futura descendencia, trunca su sueño de fundar un hogar, su propio hogar. Esa misma noche se fue de la aldea y "no se despidió de nadie" (173).

En The World, the Text and the Critic, Edward Said hace una distinción entre dos tipos de relaciones de afinidad que un individuo puede establecer con otros. Su distinción entre relaciones de filiación y relaciones de afiliación sirve, en el contexto de este ensayo, para examinar la manera como los individuos crean un imaginario tanto de hogar como nación. Said llama relaciones de filiación a los lazos que un individuo establece con ciertos lugares y grupos de personas basados en su cultura natal, es decir, en lazos determinados por lo biológico y lo geográfico. En cuanto a las relaciones de afiliación, Said menciona los lazos que se establecen con instituciones, asociaciones, comunidades y con el país natal (22-25). Obama Ondo rompe sus relaciones de filiación con su padre, primero por la muerte de su madre y segundo porque su matrimonio con la madre de Anne le destruye su sueño de fundar su propio hogar. Este mismo hecho, impide que las relaciones de afiliación que había ido construyendo con los habitantes de la aldea de su abuelo se rompan. Sin relaciones de filiación y de afiliación y, además, traicionado tanto por la cultura de sus ancestros como por la de los blancos, Obama Ondo se queda sin hogar y sin su aldea, ejes de su existencia individual y de su identidad. Por eso está condenado a moverse dentro de esos "no lugares" de la posmodernidad, el término de Augé, término al que habría que agregar otro adjetivo, el de poscolonialidad. Esto puede apreciarse en el siguiente pasaje de la novela:

Entonces asumió que había basado su vida en una quimera, en la irrealidad: se había negado a ver la decadencia inexorable de la aldea, convertida en solar de ancianidad del que huían los jóvenes; o el ocaso de su estirpe, ahogada por la doble opresión de los de dentro y los de fuera; y se percató de su ceguera ante las transformaciones inevitables, ante el imparable discurrir del tiempo, pues había luchado por mantener incólumes unas formas de pensar y un modo de vivir que no se correspondían con la simple realidad. Porque había muerto el pasado, el presente no existía ... y el futuro estaba siendo escamoteado por los ilusionistas y los manipuladores. (172)

Revista Iberoamericana, Vol. LXXX, Núms. 248-249, Julio-Diciembre 2014, 1041-1056 ISSN 0034-9631 (Impreso)

ISSN 2154-4794 (Electrónico) 
A partir de este momento, el itinerario de la vida de Obama Ondo va a estar determinado por las posibilidades de trabajo que encuentre en su siguiente destino. Lo primero que hace cuando llega a un lugar es ir al mercado a buscar trabajo. El mercado, otros de los no lugares de la postmodernidad, le proporciona una cierta estabilidad en Douala. Allí conoce a Sylvie una chica con la que tiene una relación amorosa. Cuando piensa en casarse con ella, después de conocer de su embarazo, la crisis económica que atraviesa el país, destruye su sueño de fundar un hogar con ella y lo lleva a aventurarse a emigrar a España. De allí en adelante, Obama Ondo deambulará de un sitio a otro, todos ellos dentro de la categoría de los no lugares de Augé: de polizón en un barco carguero, la cárcel para ilegales de Senegal, el avión que lo lleva a Casablanca, la furgoneta en la que atraviesa el desierto, la balsa llena de ilegales que lo conduce a Canarias, un hotel auspiciado por la ayuda de una ONG en España, las barracas en Murcia y, finalmente, el metro de Madrid. Siempre solo, consciente de no ser persona por no tener ni siquiera un pasaporte que legitime su identidad: "Se hallaba abandonado, borrado del universo, de su mundo y de cualquier otro mundo. Y eso es lo peor, el infierno mismo: convertido en un ser inexistente con plena conciencia de la existencia" (289-90). En otro momento se queja de su soledad absoluta: "Vivía como un proscrito y le pesaba la soledad. No tenía con quién compartir sus alegrías y sus tristezas, no comentaba con nadie los avatares de la jornada, no podía consultar con nadie sus proyectos, nadie escuchaba sus ilusiones, nadie le acompañaba en esos ratos entrañables en que su espíritu necesitaba esparcimientos, desahogo, efusión" (312).

Su trabajo ambulante en el metro le permite, con el tiempo, endeudarse para casarse por poder con Sylvie. Gracias a este matrimonio, Obama Ondo se reconcilia con su padre y recupera la esperanza en el futuro. Calcula que le llevaría unos cinco años para pagar su deuda y ahorrar un poco de dinero para volver a África y comprarse un terreno en Yaundé para construirse una casa decorosa. La esperanza de finalmente lograr establecer su hogar le devuelve la alegría de vivir. Al casarse, Obama Ondo establece una relación de afiliación que lo conecta no solamente con una persona, sino con su padre, con su comunidad, con su país y con su continente. De esta manera, empieza a planear su regreso:

Y volvería a su país, pondría un pequeño negocio, un bazar, una carpintería, quizás un almacén en el mercado, e iría saliendo adelante viendo el futuro con optimismo ... Ahora sabía que no existe el Edén: cada uno debe construir su propio paraíso en el lugar de su nacimiento, amparado por sus paisajes y arropado por su propio universo ... Obama Ondo estaba decidido a regresar para vivir mejor, pero no sólo él, sino todos los suyos, la tribu entera. (447)

Así mismo, el metro adquiere otra dimensión en la vida del protagonista. Deja de ser un "no-lugar" para transformarse no solamente en su sitio de trabajo sino en un

Revista Iberoamericana, Vol. LXXX, Núms. 248-249, Julio-Diciembre 2014, $1041-1056$ ISSN 0034-9631 (Impreso) 
espacio de contacto social: "Al cabo del tiempo, empezó a distinguir ciertos rostros de la multitud, y a conocer los horarios de trabajo de muchos transeúntes ... De tanto verse a diario, algunos empezaron a saludarle al pasar. Más de uno paraba un ratito para interesarse por él ... Hizo algún amiguete ocasional ... Así conoció a Lucía” (450-451).

Los "no lugares" de la postmodernidad, dice Augé, son aquellos lugares en los cuales la identidad, las relaciones y la historia tienen una importancia marginal. Obama Ondo nunca se identifica a sí mismo en toda la novela como Camerunés, siempre se ve y se refiere a sí mismo como Africano, especialmente ahora que vive como un negro entre blancos. Obligado por las circunstancias a habitar en los no-lugares de la postmodernidad en los que su existencia es inexistente, su tragedia representa no solamente la tragedia actual del continente africano sino también la de la figura cada vez más familiar del inmigrante de la sociedad de la era de la globalización: seres sin hogar, sin país y sin documentos que prueben su existencia. Seres condenados a vivir en un "no lugar" y a preguntarse, como la voz poética del poema de Carlos Alvarez, a dónde será su siguiente destino. Desgraciadamente, la vida de Obama Ondo es truncada bruscamente en el metro de Madrid, justo en el momento en que adquiere un sentido de pertenencia a su país y a su gente, y en un momento de su vida en que había logrado lo que había buscado toda su vida: un espacio de inclusión al que puede llamar hogar, así éste estuviera localizado en un lejano allá, en Camerún. Sin embargo, justo antes de su muerte trágica, Obama Ondo se encuentra en el mismo punto que se encontraba el protagonista de Las tinieblas al tomar la decisión de dejar la vida sacerdotal: soñando con la posibilidad del regreso y con la misión autoimpuesta de ayudar a salvar a su gente, a su país y por extensión a todo un continente.

Las novelas de Ndongo-Bidyogo muestran la compleja relación entre sus protagonistas africanos con su lugar de origen. Los dos han crecido en espacios ambivalentes no solamente desde el punto de vista cultural, sino también desde el punto de vista espacial. Enfrentados al choque de culturas resultado de la colonización europea, los dos optan por soluciones diferentes que, de todas maneras, los llevan al fracaso. Obama Ondo inicialmente trata de construir un hogar tradicional en la tierra de su abuelo, pero es precisamente esa tradición la que lo va llevar a perderse en los "no lugares" de la posmodernidad y lo obligará a emigrar a Europa. El protagonista de las dos primeras novelas intentará canalizar las dos culturas, es decir, adquirir la sabiduría de los blancos para salvar así a su pueblo y a sus tradiciones. Sin embargo, al regresar ya no es capaz de relacionarse con ese espacio en el que cohabitan la modernidad y la tradición, porque él mismo ha cambiado y porque el orden social, cultural y espacial que él ha imaginado para los suyos, no tiene cabida en la difícil transición experimentada por su país después de la independencia. Para los dos, hogar y nación son dos espacios mil veces recordados, recreados e imaginados a través de la memoria y, de esta manera, convertidos en utopías que nunca llegan a materializarse. La narrativa de Ndongo-

Revista Iberoamericana, Vol. LXXX, Núms. 248-249, Julio-Diciembre 2014, $1041-1056$ ISSN 0034-9631 (Impreso)

ISSN 2154-4794 (Electrónico) 
Bidyogo apunta a la dificultad de construir un futuro para los países africanos cuando el continente todavía vive las consecuencias del colonialismo y apenas está empezando a negociar no solo con su pasado colonial sino incluso con el pre-colonial en la era de la globalización. “¿Qué sería de África si todos los africanos se marchaban?”, es la pregunta que se hace Obama Ondo poco antes de morir. Esa parece ser la pregunta que se hace el propio autor sabiendo, de antemano, que hogar y nación son espacios imposibles, es decir, de exclusión, en la geografía cultural, espacial y económica del África contemporánea.

\section{OBRAS CITADAS}

Anderson, Benedict. Imagined Communities: Reflections on the Origin and Spread of Nationalism. London: Verso, 1991.

Augé, Marc. Los no lugares. Espacios del anonimato. Una antropologia de la sobremodernidad. Barcelona: Gedisa, 2000.

Fra Molinero, Baltasar. "La educación sentimental de un exilado africano: Las tinieblas de tu memoria negra de Donato Ndongo Bidyogo". Afro-Hispanic Review 19/1 (Spring 2000): 49-57.

George, Rosemary Marangoly. The Politics of Home: Postcolonial Relocations and Twentieth-Century Fiction.Berkeley: U of California P, 1999.

Grossberg, Lawrence. “Identity and Cultural Studies: Is That All There Is?” . Questions of Cultural Identity. Stuart Hall, ed. London: Sage, 1996.

Ndongo-Bidgoyo, Donato. El metro. Barcelona: El Cobre, 2007. Los poderes de la tempestad. Malabo: Morandi Editores, 1997. Las tinieblas de tu memoria negra. Madrid: Fundamentos, 1987.

Osterhammel, Jürgen. Colonialism: A Theoretical Overview. Princeton: Markus Wiener, 2005.

Said, Edward. The World, the Text and the Critic. Cambridge: Harvard UP, 1983.

Spitzer, Leo. "Persistent Memory: Central European Refugees in an Andean Land." Exile and Creativity: Signposts, Travelers, Outsiders. Backward Glances. Susan Rubin Suleiman, ed. Durham: Duke UP, 1998. 373-95.

Yeoh, Brenda S.A. "Postcolonial Geographies of Place and Migration." Handbook of Cultural Geography. Kay Anderson, ed. London: Sage, 2003. 369-80. 